\title{
Diários de aula particular e Jornal de pesquisa: Uma experiência formativa voltada ao ensino de acordeom para terceira idade
}

Private classes diaries and Journal of research:

A formative experience focused on accordion teaching for Seniors

Douglas Rodrigo Bonfante Weiss ${ }^{1}$

Ana Lúcia de Marques e Louro²

Universidade Federal de Santa Maria

\section{Resumo}

Neste trabalho apresenta-se a problematização de uma aplicação prática de Diários de Aula (ZABALZA, 2004) e do Jornal de Pesquisa (BARBOSA; HESS, 2010). Com intuito de pesquisar e teorizar sobre o ensino de acordeom voltado a alunos da terceira idade, este estudo possibilitou identificar fatores sobre a educação musical neste contexto. Foi perceptível, dentro dos diários analisados, como a qualidade da sala de aula, o mapeamento estético e a flexibilidade em relação à progressão de conteúdos auxiliam na motivação para o estudo musical.

Palavras-chave: Educação Musical; Diários de Aula; Jornal de Pesquisa, Auto formação, Terceira Idade.

\begin{abstract}
This paper presents the questioning of a practical application of Class Diaries (Zabalza, 2004) and the Journal of Research (BARBOSA, HESS, 2010). In order to research and theorize about the accordion teaching aimed at seniors students, this study identified factors on musical education in this context. It was noticeable within the journals analyzed, as the quality of the classroom, the aesthetic mapping and flexibility in relation to the progression of content assist in motivation to study music.
\end{abstract}

Keywords: Music Education; Class Diaries; Journal of research; self-education; Senior Citizens.

\section{Introdução}

Os diários de aula (ZABALZA, 2004) e o jornal de pesquisa (BARBOSA; HESS, 2010) têm se mostrado como métodos bastante satisfatórios tanto na formação de professores, como na formação de autores, tanto na Iniciação Científica quanto na Pós Graduação. Textos como Weiss e Louro (2010; 2011), estudam a formação de acordeonistas que possuíam graduação em música e, baseado nos relatos deste grupo profissional, considerei escassa a inserção do acordeom no currículo dos cursos de

Revista Digital do LAV - Santa Maria - vol. 9, n. 3, p. 119 - 139 - set./dez. 2016 ISSN 1983 - 7348 http://dx.doi.org/10.5902/1983734824319 
música do Rio Grande do Sul ${ }^{1}$. Este fato reflete na atuação do professor que atua no contexto de aulas particulares. Em busca de teorizar sobre esta prática apresenta-se a problematização de uma aplicação prática dos diários de aula e do jornal de pesquisa.

No contexto de uma cidade do interior do estado do Rio Grande do Sul, a procura por aulas de acordeom por alunos da terceira idade é frequente, sendo este um instrumento de forte representatividade cultural neste estado (REIS, 2010; BORBA, 2012). Com avanços da ciência em diversas áreas que cuidam da saúde e bem-estar, ocorreu um aumento da longevidade e as pessoas estão vivendo mais tempo na terceira idade (LUZ; SILVEIRA, 2006; ALMEIDA, 2012; ZIMERMAN, 2000). Muitas pessoas aproveitam esta fase da vida para realizar atividades que, por razões específicas, no passado não foi possível (LUZ; SILVEIRA, 2006; TORRES, 2006). Isso fez com que ocorresse uma ampliação da educação musical na fase adulta, incluindo a chamada terceira idade ou velhice. (LUZ; SILVEIRA, 2006; REIS, 2009; SOUZA, 2013).

O presente artigo foi escrito buscando, como objetivo geral, identificar fatores que contribuíram ou impediram alunos idosos de terem uma iniciação musical através do acordeom, e com intuito de pesquisar e teorizar sobre o ensino de acordeom neste contexto. A ferramenta utilizada para refletir por escrito sobre as práticas pedagógicas executadas foram diários de aula (ZABALZA, 2004). O jornal de pesquisa (BARBOSA; HESS, 2010), traz uma reflexão sobre a produção do presente texto, sobre a escrita dos diários, sobre ser professor no contexto de aulas particulares e ser aluno da PósGraduação.

Na parte inicial do texto, vou ${ }^{2}$ me deter à análise dos diários de aula. Neles buscou-se evidenciar fatores que auxiliaram na motivação e no desenvolvimento musical dos idosos, além de interpretar como a relação professor-aluno e o conforto da sala de aula auxiliaram em sua motivação. Após análise feita sobre os diários, o leitor encontrará a seção com o jornal de pesquisa, que traz reflexões sobre a construção deste texto e de todo o processo: aulas, leituras e escritas.

Quando professores ministram aulas individuais de instrumento musical, muitas vezes surgem diversas ideias e "macetes" para solução de diferentes problemas, com

\footnotetext{
1 Neste sentido surgem trabalhos como Zanatta (2004; 2005), Persch (2005; 2006), Oliveira (2008), Machado (2009), Reis (2009; 2010), Silva (2010), Puglia (2010), Borba (2013), Pereira e Nascimento (2013), com o intuito de teorizar sobre o estudo deste instrumento.

2 Parte do trabalho é escrito na primeira pessoa do singular. Esta pesquisa foi realizada pelo primeiro autor que a desenvolveu dentro de um recorte biográfico assumindo a problematização das suas vivências pessoais como parte do processo de pesquisa, o que conduz à escolha da conjugação na primeira pessoa do singular. No entanto, este artigo teve a participação direta da segunda autora, não como protagonista-pesquisadora, mas como contraponto de leitura e discussão teórica contribuindo com a escrita do texto.
}

Revista Digital do LAV - Santa Maria - vol. 9, n. 3, p. 119 - 139 - set./dez. 2016 ISSN 1983 - 7348 http://dx.doi.org/10.5902/1983734824319 
relação à aprendizagem dos alunos. Algumas destas ideias são reforçadas e agregadas para a prática do professor. Porém muitas delas se perdem com o passar do tempo, ou são esquecidas logo ao encerrar a aula. Neste sentido, os diários de aula (ZABALZA, 2004) se tornam uma ferramenta interessante para o crescimento e autorreflexão didática do professor. Além disso, o compartilhamento de ideias sobre aulas de música na terceira idade se torna interessante para aqueles que procuram atender a nova demanda destes alunos que tem sido crescente, e "por esta razão, nas últimas décadas tem-se multiplicado os estudos científicos sobre o envelhecimento" (ALMEIDA, 2012, p. $3)$.

Tenho lecionado como professor particular de acordeom há cerca de 10 anos. Neste período percebi que muitos alunos leigos, quando iniciam um curso, acreditam que o aprendizado será rápido e quase que instantâneo. Alguns destes alunos decidiram estudar um instrumento porque em outras ocasiões apreciaram instrumentistas tocando e ao fazer observações, tocar, Ihes pareceu fácil. Em aulas iniciais de instrumento musical, alguns dos alunos principiantes, ao se depararem com as habilidades motoras necessárias para execução do instrumento, demonstram um grau de desapontamento e decepção sobre esta prática. Alguns alunos em fase inicial falam em desistir, falam em "dom musical". Muitos utilizam a seguinte frase: professor seja sincero, será que tem jeito mesmo de eu aprender?

Se o professor de música não tiver um leque amplo de recursos para tornar o aprendizado do instrumento mais fácil e agradável, certamente o aluno acabará desistindo. "Nos nossos dias, o aprendiz necessita ter uma paleta alargada de experiências e uma diversidade de contextos de aprendizagem". (DAVIDSON; JORDAN, 2007, p. 743 - tradução nossa). O desenvolvimento de maneiras apropriadas de interação, tendo em vista a otimização de experiências com música, precisa ser mais atenta quando o aluno é idoso (DAVIDSON; JORDAN, 2007), ou quando se tratam de adultos que têm pesadas jornadas de trabalho. Também quando o aluno é criança e que está frequentando a aula de música não por vontade própria, mas por ser obrigada pelos pais ou outros familiares.

Todos estes contextos de aula são complexos de se trabalhar, porém, para este trabalho, foca-se em aulas para idosos. No entanto, não busco apresentar soluções para os dilemas apresentados, tendo em vista que "se referem a situações muitas vezes complexas, marcadas pela instabilidade, pela unicidade, pela particularidade dos alunos" (TARDIF, 2007, p.129).

Revista Digital do LAV - Santa Maria - vol. 9, n. 3, p. 119 - 139 - set./dez. 2016 ISSN 1983 - 7348 http://dx.doi.org/10.5902/1983734824319 
Assim sendo, busca-se através da análise dos diários de aula ressaltar alguns recursos utilizados com estes alunos em contraponto com a pedagogia presente na literatura de educação musical, considerando o diário de aula como meio para a reflexão tanto do professor que o escreve como daqueles que possam ler a análise que é feita nele.

\section{Os diários de aula}

A primeira vez que fui instigado a produzir diários de aula, foi no ano de 2008 em disciplinas de que refletiam sobre práticas educativas. A atividade de escrita dos diários foi mantida por mim após a graduação em música. Os diários de aula têm sua fundamentação teórica com base nos escritos de Zabalza (2004). Ele os define como "documentos em que os professores e professoras anotam suas impressões sobre o que vai acontecendo em suas aulas" (ZABALZA, 2004, p.13).

Sobre cada aluno de acordeom foi produzido um diário específico, e a cada aula em que apareciam inquietações maiores, o diário sobre o aluno em questão era ampliado.

Os diários de aula oportunizam ao professor narrar suas experiências docentes, o que gera uma autorreflexão sobre suas práticas, suas tensões diárias, seus objetivos de trabalho, suas expectativas e as exigências dos espaços em que está inserido. $O$ autor pondera, ainda, que

Racionaliza-se a vivência ao escrevê-la (o que tinha natureza emocional ou afetiva passa a ter, além disso, natureza cognitiva, tornando-se assim mais manejável), reconstrói a experiência, com isso dando a possibilidade de distanciamento e de análise e, no caso de desejá-lo, se facilita a possibilidade de socializar a experiência, compartilhando-a com um assessor pessoal ou grupo de colegas. (ZABALZA, 2004, p. 18).

Assim as reflexões sobre as aulas que poderiam ser apenas de "natureza emocional ou afetiva" se tornam reflexões que podem ao longo dos anos, como no caso dessa pesquisa, configurar alguns direcionamentos sobre aulas para uma determinada 
faixa etária. Além da reflexão posterior sobre as experiências e dilemas ${ }^{3}$ de ensino, o distanciamento nos permite revisitá-las após um período de amadurecimento de nossos anseios enquanto professores. Este tipo de reflexão tem uma aproximação com pesquisas acadêmicas (auto)biográficas, no sentido em que Nóvoa (1992) expõe que uma experiência, embora individual, possui aspectos que as tornam coletivas, e que fazem destes professores parte de um grupo social. "Se nós somos, se todo indivíduo é a reapropriação singular do universal social e histórico que o rodeia, podemos conhecer o social a partir da especificidade irredutível da práxis individual" (FERRAROTI, 1982 apud NÓVOA, 1992, p. 18). Nesta direção, minhas experiências podem se constituir em possibilidades de reflexão para outros professores de acordeom ou mesmo de outros instrumentos, no que tange ao ensino para alunos na terceira idade ou velhice.

Em pesquisas anteriores fiz uma revisão de autores que estudam a formação e a atuação de professores de instrumento no viés do cotidiano e educação musical, e de autores que pesquisam sobre o ensino de acordeom. Foi possível localizar como o meio familiar e o meio acadêmico interagem com as histórias de vida de professores de acordeom, problematizando como os estudos sobre este instrumento podem informar debates sobre a interface entre culturas populares e eruditas em diversos contextos de educação musical.

Estas pesquisas deram suporte para uma prática pedagógica reflexiva sobre minhas aulas de acordeom, que informaram minha formação continuada. Em busca de contribuição para com a educação musical voltada ao ensino particular de música, comecei a produzir os diários de aula no ano de 2011, sobre aulas ministradas para alunos de diferentes faixas etárias. Para esta pesquisa, foram selecionados diários de aula para alunos com idade entre 60 e 80 anos, escritos no período de junho de 2011 e abril de 2014, totalizando assim 13 diários, que foram analisados a partir da proposta de Zabalza (2004, p. 150), constando com cinco etapas descritas a seguir.

1. Construir a impressão geral sobre o que o diário conta: trata-se basicamente de uma leitura completa do diário, em função de ter uma ideia do sujeito "narrado".

2. Analisar os padrões ou as repetições: observar padrões de repetições sobre a realidade narrada, ou sobre a estrutura de escrita do diário.

3. Identificar os pontos temáticos que vão aparecendo e fazer uma leitura transversal deles. Esta etapa conta com cinco sub-etapas: a) leitura completa do texto;

\footnotetext{
${ }^{3}$ É um dilema, por exemplo, como ajustar as exigências de programas oficiais com as necessidades específicas de nossos alunos; e o é também como desenvolver a evolução de uma aluna específica (ZABALZA, 2004, p. $18)$.
}

Revista Digital do LAV - Santa Maria - vol. 9, n. 3, p. 119 - 139 - set./dez. 2016 ISSN 1983 - 7348 http://dx.doi.org/10.5902/1983734824319 
b) segunda leitura fazendo a listagem dos assuntos que identificamos no texto; c) outra leitura completa de forma seletiva recolhendo o que o diário diz sobre os assuntos identificados na etapa anterior; d) análise sincrônica e diacrônica do conteúdo, analise de como os assuntos foram evoluindo e o que se dizia à medida que ia passando o tempo; e) apresentar uma espécie de mapa sobre os tópicos analisados.

4. Analisar qualitativamente os elementos explícitos e implícitos da informação do diário.

5. Identificar os dilemas profissionais ou pessoais que aparecem no diário.

Os diários de aula foram analisados à luz destas cinco etapas, em contraponto com a literatura apresentada neste artigo sobre ensino particular de música, educação musical na maturidade e educação musical, e assim foi possível fazer uma análise reflexiva sobre os trechos dos diários de aula para aulas na terceira idade. Os contextos das aulas são uma escola de música livre no interior do estado do Rio Grande do Sul e um estúdio particular em minha casa. Em ambos os contextos as aulas foram ministradas individualmente.

\section{Reflexões sobre aulas particulares de música para terceira idade}

Indo ao encontro da etapa 5 da análise de dados, em busca de "identificar os dilemas profissionais ou pessoais que aparecem no diário" (ZABALZA, 2004, p. 150), foi possível destacar alguns fatores que foram determinantes para a iniciação musical com o grupo da terceira idade estudado. Destaco a qualidade da sala de aula, o mapeamento estético e a flexibilidade no andamento dos conteúdos e exercícios musicais.

Dos diários escolhidos para a pesquisa, foram retirados trechos relevantes e passíveis de reflexão. A subjetividade de alunos da terceira idade se torna interessante para auxiliar um possível debate sobre o ensino particular de música fora de instituições formais, indo ao encontro às práticas do cotidiano (SOUZA, 2009).

Alunos iniciantes, em geral, necessitam uma motivação extra para o aprendizado de um instrumento musical, e esse dilema pode ser intensificado quando o aluno é idoso. Portanto, um dos desafios em aulas particulares é conduzir a aula de modo que o aluno iniciante não desista de aprender. Algumas metodologias precisam ser desenvolvidas para auxiliar na motivação, transcendendo modos tradicionais de se ensinar o código ou linguagem musical.

\section{A teoria musical e a experiência sonora}

Revista Digital do LAV - Santa Maria - vol. 9, n. 3, p. 119 - 139 - set./dez. 2016 ISSN 1983 - 7348 http://dx.doi.org/10.5902/1983734824319 
Gomes (2009) em sua tese de doutorado faz um estudo sobre processos de transmissão/aprendizagem musical vividos por uma família específica ao longo de quatro gerações. Dentro do seu estudo se refere ao domínio do código musical e expõe a leitura musical como um legado importante, dentro da família por ele estudada. O autor revela que indivíduos que tocam melhor um instrumento musical e que leem música melhor, têm um status superior dentro daquela família, enquanto os integrantes com mais dificuldade se consideram "ovelhas negras", e em alguns casos, o estudo teórico afastou membros da família do estudo de música.

A importância dada ao código musical, como o domínio da leitura e escrita assim como o domínio da prática instrumental são percebidos e constatados nas falas dos entrevistados, especialmente quando, sem terem sido questionados, identificam aqueles que possuem facilidades para ler, solfejar e interpretar as músicas escritas, ou tocar peças consideradas difíceis do repertório erudito e familiar, chegando a tocar "decorado", "virtuosisticamente" e "com perfeição", identificando-as como as "mais talentosas" da família, ou aquelas que chegaram "no auge" do domínio musical. [...] Por outro lado, os que estão fora dessa lista se auto intitulam de "ovelha-negra", afirmando que "não têm talento". Ao dizerem que já haviam praticado algum instrumento, falam também do abandono da prática pelas dificuldades de aprendizado, sobretudo as relacionadas à leitura e escrita musical. (GOMES, 2009, p. 109-110).

Através da análise dos diários apareceu um caso enfático sobre a leitura musical:

Na primeira aula o aluno levantou a mão e disse: " não me dê teoria! Eu quero só aprender umas músicas!" E foi desta forma que trabalhei, simplificando muitas músicas que ele mesmo sugeria e ele ficou muito satisfeito com as aulas, e chegava nas aulas sempre de bom humor. (Diário de aula - Oliver $^{4}$ - mais de 70 anos).

No caso acima, o aluno já de começo demonstra não ter interesse no aprendizado do código musical. Porém alguns alunos têm interesse nesse estudo. Portanto não pretendemos sugerir que se abandone o ensino do código musical, mas sim sugerir que a experiência sonora e prática anteceda o estudo teórico de música, porém explicando ao

\footnotetext{
${ }^{4}$ Pseudônimo: Os nomes utilizados são pseudônimos, em busca de uma igualdade de vozes e para preservar a identidade dos alunos.
}

Revista Digital do LAV - Santa Maria - vol. 9, n. 3, p. 119 - 139 - set./dez. 2016 ISSN 1983 - 7348 http://dx.doi.org/10.5902/1983734824319 
aluno as vantagens deste estudo e deixando a critério do aluno o aprendizado ou não do código musical, fazendo uma releitura da metodologia tradicional do ensino de música

\begin{abstract}
pode-se afirmar que essa metodologia tradicional de ensino musical acaba por desestimular, em especial os idosos interessados em se alfabetizar na linguagem musical, certamente porque estes não conseguiriam, sozinhos, relacionar as duas dimensões que devem constituir o processo de cognição da Linguagem Sonora. Ao adotar esse modelo os resultados seriam insatisfatórios, pelo desestímulo dos participantes levando-os a desistir da aprendizagem, em razão das dificuldades técnicas, cognitivas e de exaustão que enfrentariam já no início do processo. (LUZ; SILVEIRA, 2006, p. 3)
\end{abstract}

Tal releitura da maneira tradicional de ensinar música refere-se a uma flexibilidade maior na sequência das atividades. É comum no ensino tradicional, iniciar pela leitura musical, pela teoria, com o domínio de escalas e arpejos, antes mesmo de tocar alguma música. Mais produtiva seria uma experimentação sonora nas aulas iniciais visando o desenvolvimento da percepção auditiva e combinatória dos sons do lado esquerdo com o lado direito do instrumento, proporcionando mais do que um simples entendimento de uma sequência escalar de notas, mas também uma experimentação sonora.

A relevância destas reflexões se dá na medida em que auxiliam os professores particulares de instrumento a trabalhar com situações onde o aluno é iniciante. Mesmo com aqueles alunos que buscam o aprendizado teórico, quando a experiência sonora e prática ocorrem antes, a motivação e o resultado para o aprendizado é mais efetivo.

Lembrando que "velhice não é sinônimo de incapacidade para a descoberta de novos interesses e aptidões, assim como é inaceitável que se associe, sem as devidas interpretações, velhice à doença, fragilidade e perda da autonomia" (LUZ; SILVEIRA, 2006 , p.15). Ou seja, os alunos na fase da velhice teriam capacidade para aprender o código musical, porém, levei em consideração a sua inclinação por fazer música sem este compromisso, o que não estava alicerçado em considera-los com limitações, mas como protagonistas de seus próprios aprendizados. Com alunos que não almejam profissionalização, o formato das aulas individuais de instrumento não necessariamente precisa seguir as maneiras tradicionais de se ensinar escalas, nome de notas e leitura musical, mas sim, que a experiência sonora seja a prioridade.

Revista Digital do LAV - Santa Maria - vol. 9, n. 3, p. 119 - 139 - set./dez. 2016 ISSN 1983 - 7348 http://dx.doi.org/10.5902/1983734824319 


\section{O cotidiano, a cultura, a faixa etária e os objetivos dos alunos}

Observando minha prática de ensino individual de acordeom, pude perceber alguns fatores relevantes para o ensino particular de música. Em uma escola livre tive 14 colegas de trabalho que lecionavam diferentes instrumentos em aulas individuais, e durante reuniões de professores, discutiam sobre suas dificuldades de ensinar. Naquelas reuniões pedagógicas percebi que, em alguns casos, os professores quando tinham dificuldade de ensinar, focavam as causas dessa dificuldade nos alunos. Em geral, atribuíam os problemas do processo de ensino e aprendizagem a dois fatores. A indisciplina no estudo em casa, e a dificuldades cognitivas e motoras do aluno.

Porém, os alunos precisam ser absolvidos como culpados de problemas como estes, e é necessário que ocorram novas reflexões sobre o cotidiano, a cultura, a faixa etária e os objetivos do aluno, verificando se está condizente com a nossa maneira de ser professor, ou seja, tanto nas relações professor aluno como com as nossas metodologias utilizadas. Lembro das falas dos colegas e acredito que esta dificuldade se intensifique quando tratamos de alunos mais idosos.

\footnotetext{
Essa aluna tinha uma facilidade extrema no aprendizado se comparada aos demais alunos iniciantes. Tinha boa flexibilidade nos dedos, e eu fiquei impressionado, perguntei como ela tinha conseguido isso, e ela então contou que por muitos anos fez datilografia no trabalho dela como secretária e que costumava ler bastante. (Diário do $1^{\circ}$ semestre de 2012 sobre Chiara - mais de 70 anos).
}

Nos diários analisados, também apareceu o caso de outro aluno que "com 20 repetições de um mesmo compasso não conseguiu memorizar uma passagem musical" (Diário do $2^{\circ}$ semestre de 2012 sobre Abel - mais de 70 anos). Este trecho pode conduzir a perguntas reflexivas: É possível que o professor insista tantas vezes em um trecho de música, sem que o aluno se sinta irritado? Que atitudes podem ser tomadas pelo professor para tornar suas aulas mais produtivas? Em alguns casos, é necessário que ocorra um novo direcionamento de conteúdos pelo professor, não deixando o aluno chegar a tal ponto exaustivo.

Certamente devido a experiências familiares, contextos culturais e outros fatores, algumas pessoas acabam tendo mais facilidade para o aprendizado musical. A motivação da maioria dos alunos iniciantes, não é a mesma que as pessoas que se tornam professores de música, tinham quando iniciaram. O estudante de música que se torna

Revista Digital do LAV - Santa Maria - vol. 9, n. 3, p. 119 - 139 - set./dez. 2016 ISSN 1983 - 7348 http://dx.doi.org/10.5902/1983734824319 
um profissional, passa por uma rede complexa de relações sociais e motivacionais até chegar a tal ponto, o que difere da maioria das pessoas que o procura para estudar música.

Eu comecei a estudar o instrumento na infância e logo, após dois anos de estudo almejei profissionalização. Então sempre tive horários regrados em casa para o estudo do instrumento. Hoje como professor, aprendi com alunos como este, a não sentir frustração, por exemplo quando o aluno esquece completamente os conteúdos anteriormente apresentados. Aprendi não transmitir frustração e impaciência para os alunos. Passei a entender a aula como momento de lazer com o instrumento, a entender que foi aquela hora de aula semanal que o aluno selecionou para tocar o instrumento, e fazer algo musical. (Diário do $1^{\circ}$ semestre de 2013 sobre Lucian - mais de 60 anos).

Ao se deparar com um aluno iniciante, é comum o jovem professor ter em mente os modelos da sua própria iniciação musical e repetir esses modelos. Por isso, além do professor buscar entender o cotidiano do aluno, tendo em mente que ele pode estar pegando o instrumento somente em aula, um importante elemento motivador é que o aluno consiga sucesso em todas as lições propostas. Assim sendo, a progressão de dificuldade das músicas e exercícios precisa ser muito sutil, sem ter a memorização como foco da aula, utilizando-se de recursos como a improvisação e o mapeamento estético, até que o iniciante possa adquirir mais sensibilidade auditiva e desenvolvimento motor para, a partir daí, aprender algumas peças fáceis.

Mesmo que o professor insista pelo estudo diário, na maioria dos casos, o aluno idoso encara a aprendizagem como momento de lazer e o estudo do instrumento acaba sendo feito somente em aula. O cotidiano do aluno adulto, em geral, já está comprometido com trabalho e família (ALMEIDA, 2012), e o aprendizado de um instrumento musical, na maioria dos casos, é tomado como momento de lazer.

\section{O mapeamento estético}

Conforme os diários, a escolha dos conteúdos e o formato da aula foram decisivos para o desenvolvimento de muitos alunos, como descrito no seguinte trecho de diário:

ele nunca conseguia pegar o acordeom fora das aulas que eram duas semanais devido a problemas que tinha que resolver em relação ao trabalho. Mesmo obtendo sucesso em algumas músicas e saindo de algumas aulas com elas decoradas, em aulas

Revista Digital do LAV - Santa Maria - vol. 9, n. 3, p. 119 - 139 - set./dez. 2016 ISSN 1983 - 7348 http://dx.doi.org/10.5902/1983734824319 
posteriores as músicas tinham sido esquecidas. (Diário do $1^{\circ}$ semestre 2013 - sobre Lucian - mais de 60 anos).

Com o aluno Lucian, as primeiras aulas foram com exercícios de iniciação básica junto ao acordeom. Após ter certo domínio motor em ambas as mãos passamos para peças fáceis, que neste caso estavam sendo esquecidas mesmo que o aluno levasse a partitura para casa. O mesmo ocorreu com Jack, como descrito no trecho a seguir:

Conversando com o aluno, questionei: "O que está havendo? Você teve facilidade para tocar e aprender esta música na aula anterior", o aluno responde: "professor, sinceramente, não tenho paciência para tocar essas músicas" (Diário do $2^{\circ}$ semestre de 2013, Jack mais de 60 anos).

O mapeamento estético é fundamental para manter os alunos de qualquer faixa etária interessados e motivados durante as aulas, e esse mapeamento pode ser feito nas aulas iniciais, o que vai gerar boas expectativas. É importante reconhecer a cultura dos alunos, seu gosto musical e sua principal motivação social para procurar aulas de instrumento. Desta forma expõe Subtil (2006) ao citar Bourdieu:

Bourdieu (1997) considera que o que chamamos gosto é na verdade um "senso prático" [...] esquemas de ação que orientam percepções, escolhas, respostas". Enquanto propensão à apropriação - material e/ou simbólica - de objetos e práticas é o que está na base do "estilo de vida", corresponde às diferentes posições (distinção) ocupadas no espaço social, e é uma retradução simbólica das diferenças objetivas das condições de existência [...] o gosto que informa as práticas culturais é uma questão de classe e de posição que o sujeito ocupa na sociedade capitalista (SUBTIL, 2006, p. 23).

Conhecer o gosto musical do aluno significa valorizá-lo, e conhecê-lo. No caso dos alunos aqui estudados, foi feita uma listagem de músicas favoritas, que poderiam ser futuramente estudadas. Através dessa experiência constatou-se que muitas músicas sugeridas acabam sendo de um grau de dificuldade superior à habilidade do aluno, o que aconteceu no caso do aluno Jack. Então a ele foram sugeridas músicas que tradicionalmente se ensinam para alunos iniciantes, e isso surtiu um resultado negativo.

Criar arranjos facilitados das músicas sugeridas pelo aluno, que em casos de dificuldade extrema, podem ser tocadas somente na mão direita, enquanto o professor executa a mão esquerda ajudou no desenvolvimento dos mesmos. Os arranjos facilitados

Revista Digital do LAV - Santa Maria - vol. 9, n. 3, p. 119 - 139 - set./dez. 2016 ISSN 1983 - 7348 http://dx.doi.org/10.5902/1983734824319 
das músicas sugeridas além de deixarem os alunos satisfeitos com o estudo, ao mesmo tempo contribuem para exercitar a coordenação motora. Alguns diários analisados, mostram que a aula seguiu somente as músicas sugeridas pelo aluno, tornando-se uma terapia musical:

O que funcionou com este aluno foram melodias em Do e Sol maior apenas na mão direita. E a aula foi sempre tida como uma terapia musical. Seguindo nesta mesma linha de raciocínio com iniciantes tive mais uns 4 alunos. Ou seja, se recusam a aprender como realmente deve ser a progressão com músicas simples e preferiram "brincar" com o instrumento apenas na mão direita com algumas melodias conhecidas. (Diário do $1^{\circ}$ semestre de 2013, Jack mais de 60 anos).

O "brincar com músicas", como um exercício menos formal, pode se tornar mais interessante do que manter-se na mesma postura tradicional em relação à progressão correta no ensino de um instrumento. Além do mapeamento estético é importante conhecer o cotidiano do aluno (SOUZA, 2009) e suas possibilidades de tocar o acordeom em casa, especialmente quando o aluno é idoso e trabalha. Esses fatores são revelados no seguinte trecho de diário:

É um dos meus alunos com mais dificuldade. Trabalha como construtor e segundo ele, chega em casa tarde e muito cansado, além de ter vizinhos muito próximos. Estes fatos o impedem de pegar o acordeom em casa. Gosta de sugerir músicas para aula e muitas delas são aprendidas somente no teclado (mão direita) do acordeom. (Diário - $1^{\text {a }}$ semestre de 2014 - Derek mais de 60 anos).

Em outro caso, do aluno Oliver, seu médico recomendou buscar formas de descontração. Então as aulas de acordeom foram escolhidas:

Ele contou que as aulas de acordeom ajudaram muito seu sistema nervoso, isso segundo médicos e familiares. Com este aluno resolvi não trabalhar com nomes de notas e escalas, tendo em vista que várias escalas ele havia aprendido intuitivamente e não queria teorizar. (Diário de aula - Oliver- mais de 70 anos).

Conforme os diários analisados, a abordagem terapêutica da música nas aulas tem auxiliado na motivação de alunos idosos. Este aspecto também é descrito em Cirino (2010), que complementa esta ideia expondo que

Revista Digital do LAV - Santa Maria - vol. 9, n. 3, p. 119 - 139 - set./dez. 2016 ISSN 1983 - 7348 http://dx.doi.org/10.5902/1983734824319 
os aspectos musicais não precisariam estar ligados particularmente ao tratamento de enfermidades para servirem como recurso terapêutico. Provavelmente, benefícios como relaxamento, entretenimento, bem-estar e aumento da autoestima podem influenciar na capacidade intelectual do aprendiz no estudo formal de música. A música, portanto, tem um papel valioso no processo de musicalização dos adultos com mais idade, abrangendo propriedades relacionadas à cognição, emoção e ao contexto social. (CIRINO, 2010, p.120).

Foi perceptível, dentro dos diários analisados, como o mapeamento estético e a flexibilidade em relação à progressão de conteúdos auxiliam na motivação para o estudo musical. Deixar os alunos mais livres com relação ao fazer musical, dando a eles uma hora descontraída junto ao instrumento pode se tornar mais valioso para o aluno do que realmente ensinar o instrumento "como deve ser ensinado".

\section{Qualidade da sala de aula}

Destaca-se a importância do conforto da sala de aula para um instrumento como o acordeom. Por ser um instrumento pesado e ficar bem junto ao corpo é importante ter uma sala climatizada, com cadeiras estofadas. Pode-se constatar que uma sala de aula visualmente bem arrumada e equipada com isolamento acústico ajuda muito na satisfação dos alunos de instrumentos musicais - um fator bem destacado em diários e reflexões sobre aulas de alguns alunos como Abel, com mais de 70 anos.

Um dos fatores que certamente influenciou na sua desistência foi a troca da sala de aula, a primeira era com isolamento acústico e bem ampla, que em função da demanda da escola foi necessário mudar. O aluno reclamava dizendo: "Mas agora nossa aula é sempre nesse esconderijo apertado?". (Diário do $2^{a}$ semestre de 2012 sobre Abel, com mais de 70 anos).

Conforme observei nos diários, o início do inverno no Estado do Rio Grande do Sul ${ }^{5}$ pode ser um fator que influencia alunos idosos a parar de tocar. Portanto, prestar a atenção na climatização da sala pode reduzir o índice de desistência. O aluno Oliver "ficou muito satisfeito com as aulas, e chegava aulas sempre de bom humor, mas avisava perto dos meses junho que no inverno não viria. Segundo ele, com o frio ficaria

\footnotetext{
${ }^{5}$ No Estado do Rio Grande do Sul a estação do inverno atinge temperaturas próximas ou abaixo de zero graus.
}

Revista Digital do LAV - Santa Maria - vol. 9, n. 3, p. 119 - 139 - set./dez. 2016 ISSN 1983 - 7348 http://dx.doi.org/10.5902/1983734824319 
em casa perto do seu fogão a lenha." (Diário do $1^{\text {a }}$ semestre de 2013 sobre Oliver, com mais de 65 anos.

Com relação às salas, nas aulas ministradas em casa, mesmo que em estúdio com isolamento acústico apropriado, um problema enfrentado foi o da "sala de espera". Muitos alunos chegam antes do horário previsto (e alguns dependem de carona de outras pessoas acabam, por vezes, tendo que esperar até uma hora após o término da sua aula) o que pode ser bastante desagradável se não fizermos o acolhimento na chegada e a despedida quando o aluno vai para sua casa.

O professor que trabalha em casa preocupa-se com regras de horário, disciplina, o controle do tempo da aula, onde até mesmo a espera daqueles alunos que chegam antes ou estão aguardando alguém para buscá-los precisa ser pensada e, segundo os depoimentos, são preenchidas com alguma atividade, seja ler uma revista, ouvir música ou até fazer exercícios de teoria. (BOZZETTO, 2004, p. 38).

É perceptível a importância da sala de espera, já que em um breve período de aulas foram enfrentados alguns problemas neste sentido. "Trabalhar na própria casa é muito confortável para alguns professores particulares porque não precisam sair para a rua, mas transformá-la em local de trabalho traz alguns problemas." (BOZZETTO, 2004, p.35). Portanto, além da didática durante a aula, o conforto, a climatização da sala, a recepção e a despedida são fatores que também fazem parte do processo de aprendizagem.

\section{O jornal de pesquisa: o processo de construção do texto}

Como mencionado anteriormente, os diários de aula foram escritos no período de junho de 2011 e abril de 2014. No ano de 2016, enquanto Doutorando em Educação, o trabalho de escritas e reflexões continua. Conheci o trabalho de Barbosa e Hess (2010), que aborda o "Jornal de Pesquisa", e os "Diários de Pesquisa", que são bastante semelhantes. O diário remete ao sentido de uma escrita pessoal e intima, voltado ao autoconhecimento, o jornal é uma escrita informativa voltada a um público específico, ou seja, um diário que também pode ser voltado à publicação.

O jornal de pesquisa (JP) visa englobar as nossas "tempestades mentais", e pode registrar as várias etapas da construção de um plano de aula, de um livro ou um artigo por exemplo. Visa possibilitar a reflexão sobre situações, fatos, ideias ou constatações

Revista Digital do LAV - Santa Maria - vol. 9, n. 3, p. 119 - 139 - set./dez. 2016 ISSN 1983 - 7348 http://dx.doi.org/10.5902/1983734824319 
que nos marcam e nos causam impressões. Possibilita registrar e compartilhar nossas relações com uma circunstância ou várias.

A prática do JP se insere numa outra perspectiva de entender e de
fazer ciência, que se caracteriza por apresentar posições opostas
em relação à linguagem matemática e ao isolamento do sujeito.
Nessa outra perspectiva, entram em cena a pesquisa qualitativa, a
postura hermenêutica e interpretativa e a incorporação da
presença do observador com todas suas implicações, apresentando
como resultado um conhecimento não objetivo no sentido
matemático, mas hibrido, mestiço, resultante da mistura de razão
e subjetividade do observador[...]. Precisamos avançar nesse
procedimento de ver a nós mesmos, enquanto olhamos nossos
objetos de interesse e interrogação. Assim, tão importante quanto
darmos conta do mundo que nos é exterior é avançarmos no
conhecimento de nós mesmos. (BARBOSA; HESS, 2010. p. 32-
33).
(BARBas,

A esse conhecimento híbrido e mestiço podemos relacionar a ideia de Multirrefencialidade trazida em Barbosa e Hess (2010), sugerindo que a realidade pode ser vista não a partir de um ponto único de entendimento ou forma única de colocá-la em prática. Na Multirreferencialidade, o que está em questão, o que está em foco, é o homem-sujeito e tudo o que tange suas relações, pensando na complexidade do homem (razão, emoção, objetivo e subjetivo ao mesmo tempo). Em um JP refletindo sobre a importância da escrita de diários e como a análise feita contribuiu para minha formação registrei:

Escrevendo este artigo, e olhando para esses diários de aula (2011-2014), lembro do passado quando comecei a dar aulas particulares por volta 2004 e vejo que a reflexão através de diários me amadureceu enquanto professor. Comecei a perceber nuances da aula que antes passavam despercebidas, ou eram ignoradas, eram problemas que aparentemente eram comuns e continuavam sendo apenas problemas, onde o culpado das dificuldades, da estagnação ou não evolução junto ao instrumento, era o aluno. Escrever os diários fez com que eu olhasse mais para mim mesmo enquanto professor repensasse minha didática e me fez também refletir sobre a vida cotidiana de cada aluno. Quando comecei a dar aulas de instrumento na minha adolescência eu tinha medos que hoje não tenho mais. Comecei a enxergar possibilidades de um tempo mais lento de aprendizagem, de alunos que contam histórias, de circunstâncias da vida, da música ser parte de um lazer. Passei a me ver como amigo dos alunos, que vem para aula como se fosse uma visita a um amigo, para conversar, aconselhar

Revista Digital do LAV - Santa Maria - vol. 9, n. 3, p. 119 - 139 - set./dez. 2016 ISSN 1983 - 7348 http://dx.doi.org/10.5902/1983734824319 
ser aconselhado sobre o cotidiano, ou apenas para ouvir e também estudar música. (Diário de Pesquisa, agosto de 2016).

Me emociono ao saber que hoje muitos alunos me consideram um grande amigo. E isso aconteceu através das minhas mudanças de postura enquanto professor. Ou seja, realmente tratar os alunos como amigos. Confesso que entre "trinta e tantos" alunos isso pode ter me prejudicado com dois ou três alunos no sentido de atrasarem o pagamento das mensalidades de aula, e isso pode ter ocorrido pelo excesso de confiança criado entre professor e aluno. (Diário de Pesquisa, dezembro de 2016).

Nos trechos anteriores percebe-se múltiplas questões que envolvem a autoformação, como a relação professor aluno, e a relação do professor consigo mesmo. O apontamento de problemas, aflições e como se deu a resolução dos mesmos são parte do processo formativo. Fraquezas que acabamos escondendo, e o JP serve para compartilharmos algumas dessas inquietações, ou seja:

as armações, os monturos, os cacos de pedras, blocos de cimento e pedaços de madeira que foram se amontoando durante 0 percurso até que a "casa" ficasse pronta[...] sempre nos ensinaram, nossos professores e nossos pais, que não devemos mostrar nossas fraquezas, nossos medos... Mas se tratando da nossa formação, com sentido principalmente para nós mesmos, esses cacos e amontoados de coisas também fazem parte da construção. Da nossa construção. (BARBOSA; HESS, 2010, p. 35)

Refletir por escrito as dificuldades da docência nos transforma enquanto professores. É uma prática que nos dá preparo para dar aulas. Como exemplo, o preparo para orientar uma pessoa com dificuldades de aprendizagem, ou com uma agenda muito corrida. A reflexão por escrito proporciona uma dinâmica de observar cada aluno e a si mesmo com um olhar crítico. E no caso do presente trabalho, um olhar mais profundo e reflexivo sobre o que o aluno busca com as aulas, sobre o gosto estético e sobre seu cotidiano.

A reflexão por escrito me fez perder a insegurança em minhas posições enquanto professor. Um exemplo: eu tinha medo de ser muito duro com o aluno, ou de dizer algo que o magoasse. Teve casos de alunos com instrumento bastante inadequado, e o acordeom é um instrumento de valor comercial bem alto, e eu me preocupava em sugerir troca ou compra de outro instrumento, pois tinha medo de afastar o aluno do estudo do mesmo. Comecei a ter regras pré-pensadas para cada situação, e também em exceções das regras, ser maleável enquanto professor, e o quanto de 
maleabilidade é possível ter sem ser injusto tanto comigo mesmo como com os alunos. Em relações interpessoais sempre ocorrem situações que exigem uma tomada rápida e quase instantânea de decisão, e ter um preparo por escrito de qual será tomada, ou qual foi a decisão tomada, bem como a consequência dessas decisões em cada situação das aulas tem sido também um exercício muito importante. (Diário de Pesquisa, agosto de 2016).

Neste sentido a produção dos diários de aula também serve como ferramenta para nos vermos no que fazemos, no sentido da autoformação e recriação tanto profissional quanto pessoal. Tanto a produção como a análise e seleção de diários nos transforma e reinventa nossa maneira de ser perante as situações e dificuldades, somos nossos próprios professores, nos auto avaliamos e, no presente texto, compartilhamos e analisamos inquietações que surgiram em aulas particulares de instrumento musical. Reflexão que também pode servir para diversos contextos de ensino e aprendizagem.

aprender a lidar, expor, a desdobrar, a jogar com nossas implicações, para que aquilo que produzimos seja uma extensão nossa e vice-versa. Para que tenha sentido. Assim, aprenderíamos a nos ver naquilo que fazemos e poderíamos também exercitar sobre a aprendizagem prazerosa da novidade que é nos vermos no que fazemos, e o que fazemos ser extensão do que somos. (BARBOSA; HESS, 2010, p. 36)

\section{Considerações finais}

A utilização de diários de aula tem se mostrado efetiva tanto para a auto formação e auto avaliação crítica do professor, como para o conhecimento das particularidades e dificuldades de cada aluno, buscando a adequação e flexibilidade da didática em cada caso especifico.

Os diários contribuíram para conhecer as expectativas do aluno iniciante na terceira idade em relação as aulas e ao instrumento, seu tempo disponível para a prática do mesmo fora dos horários de aula, bem como sua preferência musical, visando assim uma maior adesão e interesse nas aulas. Isso só se torna possível através de um diálogo aluno-professor e posterior planejamento através de diários de aula levando em consideração os objetivos e individualidade de cada aluno, uma vez que, tratando-se de aprendizado cada um tem sua peculiaridade, o que deve ser levado em conta na hora de ministrar as aulas e as lições bem como suas evoluções.

Revista Digital do LAV - Santa Maria - vol. 9, n. 3, p. 119 - 139 - set./dez. 2016 ISSN 1983 - 7348 http://dx.doi.org/10.5902/1983734824319 
No caso de alunos de terceira idade a flexibilidade precisa ser maior, levando em consideração as responsabilidades laborais e familiares, bem como as atividades extras e estresses de alguns alunos, que, influem diretamente no seu nível de atenção no professor e nas aulas, e consequentemente, no conhecimento absorvido e em seu ritmo de aprendizado. A aprendizagem depende do grau de atenção que a pessoa consegue depositar no professor, e também do grau de absorção do conhecimento que a pessoa possui. Se o aluno apresenta sinais de estresse, sua atenção e seu rendimento em aula serão negativamente afetados. Algumas pessoas possuem momentos de pensamentos e de reflexão introspectiva e nesses momentos elas ficam desligadas para estímulos externos, portanto o professor é desafiado a observar se o aluno realmente está prestando atenção, ao explicar algo. Dentre muitos fatores, a concentração do aluno, também depende do grau de exercício cognitivo que ele teve no passado, e também do grau de instrução da pessoa, e esse grau de atenção influenciará na sua aprendizagem. Aprendi nessas reflexões a observar mais o aluno sobre como ele se encontra enquanto pessoa e não apenas para os seus dedos e o resultado sonoro de sua música.

Através de anotações de diários de aula foi possível avaliar outros fatores importantes no aprendizado de instrumento, como um ambiente agradável visualmente, cadeira confortável devido ao tamanho e peso do instrumento, bem como uma sala climatizada. Além disso, a recepção e despedida são aspectos importantes.

É importante reafirmar as possibilidades de encaminhamentos de dilemas típicos da aula de música através da escrita de diários e análise dos mesmos. Os diários de aula, além de servirem como recurso de planejamento e acompanhamento de aulas ou ferramenta para auto avaliação, pode servir também como "matéria-prima" para o Jornal de Pesquisa, visando compartilhar experiências e incitando a reflexão de outros profissionais da área a fim de otimizar a sua didática e consequentemente os resultados almejados.

Foi este processo de tornar uma experiência didática pessoal em uma possibilidade de compartilhamento com a comunidade acadêmica que vivenciei ao longo dessa pesquisa. Por um lado, muitos questionamentos sobre os alunos na terceira idade aprendendo o instrumento acordeom vieram à tona; por outro, meu processo reflexivo como professor espelhou as modificações que minha metodologia sofreu ao longo dos anos a partir dessas ponderações. Espero contribuir para os debates em torno do ensino de instrumentos musicais em aulas individuais, especialmente no que se refere ao acordeom na terceira idade, bem como com as discussões em tornos das possibilidades

Revista Digital do LAV - Santa Maria - vol. 9, n. 3, p. 119 - 139 - set./dez. 2016 ISSN 1983 - 7348 http://dx.doi.org/10.5902/1983734824319 
abertas pelos diários de aula ou jornais de pesquisa para a pesquisa qualitativa na área de Educação Musical.

\section{REFERÊNCIAS}

ALMEIDA, Marta Sofia Moreira de. As Universidades Da Terceira Idade: Novas Aprendizagens Ou Centros De Convívio. Dissertação de mestrado em ciências da educação. Faculdade de Ciências Sociais e Humanas, Universidade de Lisboa, Março, 2012.

BARBOSA, J. G. HESS, R. O Diário de Pesquisa: o estudante universitário e seu processo formativo. Brasília: Liberlivro, 2010.

BORBA, Ronison E. Ensino de acordeom no Rio Grande do Sul: Breve análise de quatro métodos. Monografia de Conclusão de Curso. Universidade Federal de Santa Maria, Centro de Artes e Letras, Departamento de Música: Santa Maria - RS, 2013.

BOZZETTO, Adriana. Ensino Particular de Música: práticas e trajetórias de professores de piano. Porto Alegre: Ed. URGS, 2004.

CIRINO, Andréa Cristina. Musicalização na maturidade: vivência e aprendizagem musical. Dissertação apresentada ao Programa de Pós-Graduação da Escola de Música da Universidade Federal de Minas Gerais Universidade Federal de Minas Gerais Escola de Música, Belo Horizonte, 2010.

DAVIDSON, Jane W; JORDAN, Nicole. "Private Teaching, Private Learning" An Exploration of Music Instrument Learning in the Private Studio Junior and Senior Conservatories. In: BRESLER, Liora (org). International Handbook of Research in Arts Education. Volume 16. Part. 1. U.S.A: Springer, 2007 , P.729-754.

GOMES, Celson. Educação musical na família: as lógicas do invisível. Tese de Doutorado - Universidade Federal do Rio Grande do Sul, Porto Alegre, 2009.

LOURO, Ana Lúcia de Marques e. Cartas de licenciados em música: (re)contando o vivido para centrar a aula no aluno. Revista da ABEM, Porto Alegre, V. 20, 63-68, set. 2008.

LUZ, Marcelo Caíres. SILVEIRA, Nadia Dumara Ruiz. Educação Musical na Maturidade. in: CÔRTE, Beltrina; MERCADANTE, Elisabeth Frohlich; ARCURI, Irene Gaeta (Org.). Masculin(idade) e velhices: entre um bom e mau envelhecer. São Paulo: Vetor, 2006 (Coleção Gerontologia, 3).

MACHADO, André. V. Ensino de acordeon: um estudo a partir da prática docente de dois professores. Monografia (Graduação em Música: Licenciatura) - Universidade Estadual do Rio Grande do Sul, Montenegro, 2009.

Revista Digital do LAV - Santa Maria - vol. 9, n. 3, p. 119 - 139 - set./dez. 2016 ISSN 1983 - 7348 http://dx.doi.org/10.5902/1983734824319 
NÓVOA, António. Os Professores e as Histórias da sua Vida. In: NÓVOA, A. Vidas de Professores. Porto: Porto, 1992. p.11-30.

OLIVEIRA, Jeferson. Músicas Solos de Acordeon do CD Minha Cordeona. Volume 1. Carazinho - RS, 2008.

PERSCH, Adriano J. A música de Albino Manique: Doce Saudade. Volume 1. Álbum de Partituras. Porto Alegre: Comissão Gaúcha de Folclore, 2005.

Adriano J. O ensino particular de acordeon auxiliado por computador: Um estudo de caso utilizando o software Encore. Montenegro: Curso de Graduação em Música - Licenciatura. Fundação Municipal de Artes de Montenegro - FUNDARTE, 2006. (Monografia de conclusão de curso)

PEREIRA, Júlio Cesar Pires; NASCIMENTO, Flávia Marchi. O acordeom na educação musical: perspectivas para uma formação inicial no ensino superior. Revista da Fundarte, $n^{\circ} 26$, jul/dez 2013, p. $73-89$.

PUGLIA, Eduardo Faleiros. O ensino do acordeom na região sudeste do Brasil. Monografia (graduação) - Universidade de Ribeirão Preto. UNAERP, Licenciatura plena em música. Ribeirão Preto, 2010.

REIS, J. T. Aulas de acordeom na terceira idade: uma abordagem reflexiva sobre um caso específico. In: CONGRESSO NACIONAL DA ABEM, 18., e SPEM, 15., 2009, Londrina. Anais..., Londrina: Abem, 2009. p. 320-328.

A abordagem do conceito de harmonia tonal nos processos de ensino e aprendizagem... . In: XIII Encontro Regional da ABEM- Sul. Anais... Porto Alegre: ABEM SUL, GT7-Formação do professor em espaços não escolares; 2010.

SOUZA, Jusamara (Org.). Aprender e ensinar música no cotidiano. Porto Alegre: Editora Sulina, 2009.

SUBTIL, Maria José Dozza. Música midiática e gosto musical das crianças. Ponta Grossa: Editora UEPG, 2006.

SILVA, Álvaro C e. O ensino de acordeom no Brasil: uma reflexão sobre seu material didático. (monografia de conclusão de curso). Departamento de Música da Escola de Comunicações e Artes da Universidade de São Paulo - USP, 2010.

TARDIF, M. Saberes Docentes e Formação Profissional. Petrópolis: Editora Vozes, 2007.

TORRES, Maria Cecília de A. Rodrigques. Narrativas de Valsa: um relato de caso acerca do processo de musicalização na vida adulta. Expressão - Revista Do Centro De Artes e Letras da Ufsm, V.1, ANO 10, JAN/JUN/2006, P. $102-107$.

WEISS, Douglas. R. B; LOURO, Ana. A formação e atuação de professores de acordeom na interface de culturas populares e acadêmicas. Revista da Abem n²6, Jul. Dez, 2011.

Revista Digital do LAV - Santa Maria - vol. 9, n. 3, p. 119 - 139 - set./dez. 2016 ISSN 1983 - 7348 http://dx.doi.org/10.5902/1983734824319 
WEISS, Douglas Rodrigo Bonfante. A formação e a atuação de professores de acordeom de Santa Maria - RS: Interface de culturas populares e acadêmicas. Monografia (Graduação em Música: Licenciatura) Universidade Federal de Santa Maria, Santa Maria, 2011.

ZABALZA, Miguel. Diários de Aula: um instrumento de pesquisa e desenvolvimento Profissional. Porto Alegre: ArtMed, 2004.

ZIMERMAN, Guite I. Velhice - aspectos biopsicossociais. Porto Alegre: Artes Médicas Sul, 2000.

ZANATTA, Maria. A. F. Dialetos do acordeão em Curitiba: Música, cotidiano e representações sociais. Dissertação (Mestrado em Ciências Sociais), Universidade Estadual de Ponta Grossa. Ponta Grossa, 2005.

O acordeon no cenário político, econômico e sócio cultural brasileiro. Revista Emancipaçâo V. 4 No 1 (2004) Disponível em <http://www.revistas2.uepg.br/index.php/emancipacao/article/view/57> acessado em 24 de junho de 2010.

${ }_{1}^{1}$ Possui graduação em Bacharelado em Música pela Universidade Federal do Rio Grande do Sul (1991), mestrado em Música pela Universidade Federal do Rio Grande do Sul (1995) e doutorado em Música pela Universidade Federal do Rio Grande do Sul (2004). Atualmente é professor associado da Universidade Federal de Santa Maria. Tem experiência na área de Artes, com ênfase em Educação Musical, atuando principalmente nos seguintes temas: narrativas de si, educação musical, formação de professores, identidades profissionais e cursos superiores de música. É membro das associações ISME, ABEM, ANPPOM, ANPED, BIOGraph.

2Possui graduação em Bacharelado em Música pela Universidade Federal do Rio Grande do Sul (1991), mestrado em Música pela Universidade Federal do Rio Grande do Sul (1995) e doutorado em Música pela Universidade Federal do Rio Grande do Sul (2004). Atualmente é professor associado da Universidade Federal de Santa Maria. Tem experiência na área de Artes, com ênfase em Educação Musical, atuando principalmente nos seguintes temas: narrativas de si, educação musical, formação de professores, identidades profissionais e cursos superiores de música. É membro das associações ISME, ABEM, ANPPOM, ANPED, BIOGraph.

Enviado em: 06 de outubro de 2016.

Aprovado em: 27 de novembro de 2016.

Revista Digital do LAV - Santa Maria - vol. 9, n. 3, p. 119 - 139 - set./dez. 2016 ISSN 1983 - 7348 http://dx.doi.org/10.5902/1983734824319 